\title{
A Study of Visitors' Leisure Travel Behavior in the Northwest Territories of Canada
}

\author{
Jeffrey J. LaMondia \\ Auburn University \\ Department of Civil Engineering \\ 238 Harbert Engineering Center, Auburn, AL 36849-5337 \\ Phone: (334) 844-6284; Fax: (334) 844-6290 \\ E-mail: jlamondia@auburn.edu
}

\author{
Chandra R. Bhat* \\ The University of Texas at Austin \\ Department of Civil, Architectural \& Environmental Engineering \\ 1 University Station, C1761, Austin, TX 78712-0278 \\ Phone: (512) 471-4535, Fax: (512) 475-8744 \\ Email: bhat@mail.utexas.edu \\ *Corresponding Author
}

November 1, 2010 


\begin{abstract}
As long-distance leisure travel has shifted to being broader and more of an amalgam of different activity types, it has become critical for planners to understand what combinations of activities individuals will most likely participate in during a leisure trip. Accordingly, this study models travelers' participation in any combination of eight leisure trip activities. The analysis utilizes activity participation data from a tourist exit survey collected from the Northwest Territories in Canada. A Multivariate Binary Probit model system, with correlation across every pair of leisure activities, is estimated using a Composite Marginal Likelihood method. The empirical analysis results emphasize that travelers often combine specific sets of leisure activities together during tourism travel. However, which sets of activities get paired together depends greatly on travelers’ experience, travel companions, and individual concerns.
\end{abstract}

Keywords: Tourism travel behavior, combined leisure activity involvement, prior travel experience, Composite Marginal Likelihood, Multivariate Binary Probit. 


\section{INTRODUCTION}

The tourism-related literature frequently highlights the observation that, over the past decade, long-distance leisure travel has become commonplace for many households. In particular, many individuals and households now view tourism travel as an extension of their daily activities (Larsen, 2008, LaMondia and Bhat, 2010). This shift in tourism-related pursuits from being an occasional focused getaway during the year to becoming a more integral part of routine living may be attributed, at least in part, to the constraints imposed by the economic downturn. However, there are also other elements driving this trend of making tourism-related pursuits a part of daily living, and pursuing such activities relatively close to home. Specifically, not only does the resulting compact geographic footprint entail less expenditure per tourism pursuit, but such close-to-home pursuits also require less pre-planning and less time investment per pursuit. The latter issue is of particular relevance because long vacation time investments are possible only during a few full weeks during the year (and these weeks are determined, among other things, by work schedule considerations in multiple worker households, and additional children's school schedule and activity considerations in households with children). At the same time, the types of activities being pursued during these relatively short long-distance leisure travel have shifted from being narrow and specific to being broader and more of an amalgam of different activity types (Hwang and Fesenmaier, 2003; Hellstrom, 2006). In effect, travelers perceive pursuing a "suite of activities" (especially those “off the beaten path”) as a more effective use of their leisure time, as rejuvenating, and as intellectually stimulating (Outcrop, 2007). The net result is that tourism travel is now more complex, and it has become important to understand what combinations of activities individuals will most likely participate in during a leisure trip (in this paper, we will use the label "leisure trip" and "leisure pursuit" synonymously, rather than in the traditional use of a trip as a one-way travel between two points separated in space). Unfortunately, the "how and why" of combining activities during tourism travel has been relatively unexplored in the literature.

The prediction of tourism activity participation is of particular interest to transportation planners because tourism travelers' behavior and preferences play a significant role in local and regional economies, traffic congestion, and growth (Kuhimof and Wassmuth, 2002). Individuals primarily select destinations based on what leisure activities are available as well as their perceived image of these activities. Their involvement can, in turn, impact other travelers' 
perceived destination image, environment and social character (Fennell, 1996). As such, planners need to understand what activities (or combinations of activities) tourists are interested in, so that they can inform the development of regions accordingly. At the same time, decisionmakers must be careful when developing destinations to not overly diversify to the point of creating internal competition among activities (Dupuis, 2004). Furthermore, decision-makers must carefully balance the need between attracting travelers and commercializing on the one hand and maintaining the region's original pristine identity (e.g. natural beauty) on the other (Fennell, 1996).

To address this complicated situation, planners are turning to forecasting models that predict tourism travel demand and activity participation based on individuals' travel behavior. The main focus of these activity-based travel models is on predicting individuals' complete activity-travel schedule over a given period of time. These models are responsive to policy, development, and planning factors, which allow practitioners to more accurately and effectively predict how changes will affect regional sustainability and growth. Aptly, a significant component of these models is focused on understanding the combinations of activities in which individuals participate. Unfortunately, most of the previous work on leisure activities is split between focusing on broad trip purposes or only considering a single activity from the overall trip (Lew and McKercher, 2006). For instance, it has been shown that social leisure activities cover a wide spectrum of activities, and while this single activity category is often used in models, it is often an amalgamation of many leisure activities (Kemperman et al., 2006). Therefore, to better develop tourism demand models, researchers need to understand long distance leisure activity participation and the factors that influence which activities travelers commonly combine during a tourism trip.

The current study addresses this gap in knowledge by modeling travel parties' participation in combinations of eight relatively disaggregate leisure trip activities: cultural pursuits, touring, shopping, sightseeing, wildlife experience, land recreation, water recreation, and hunting/fishing. The analysis utilizes activity participation data from a tourist exit survey collected from the Northwest Territories (NWT) in Canada. We use a Multivariate Binary Probit (MBP) model system in the modeling, with recognition of the correlation across each and every pair of leisure activities. The MBP system is estimated using a fast, practical, and flexible Composite Marginal Likelihood method, which develops a surrogate likelihood function by 
compounding likelihoods for each pair of leisure activities and combining these marginal likelihood objects.

The rest of this paper is structured as follows. The next section introduces the current knowledge on combinations of activities pursued during tourism travel. Section 3 describes the formation and characteristics of the sample from the Northwest Territories exit survey. Next, the methodology for the Composite Marginal Likelihood (CML) method for estimating model parameters is described in Section 4. Section 5 presents the empirical results, and the paper concludes in Section 6 with a summary of findings and recommended future work.

\section{COMBINING LEISURE ACTIVITIES}

Tourism travel is a unique form of trip-making. As one would expect of these trips, individuals tend to travel farther and spend longer at their leisure destinations relative to daily travel to a grocery store or to a gym. These tourism travel characteristics result in varying trip-activity structures, different constraints, and distinct travel motivations (relative to daily travel patterns). First, in terms of trip-activity structures, tourism trip-activity structures can be described as having two levels: long- and short-distance activity components. The long-distance activity component of this type of travel describes individuals' choice of main trip purpose, primary transport mode, and primary destination (Herriges and Phaneuf, 2000). Once individuals reach their destination, they then decide which activities to pursue on a daily basis as part of the shortdistance activity component (Erhardt et al., 2007). Decisions at both levels are made to maximize the number and quality of activities individuals can participate in during their trip (Simma et al., 2002). The importance of participating in a range of activities is further demonstrated by travelers' trip-chaining and destination-chaining behavior (Hwang and Fesenmaier, 2003; Hackney, 2004). Second, in terms of constraints, tourists face a variety of constraints associated with tourism travel that affect their activity involvement, including a set timeframe, budget limitations, experience with the destination and/or activities, transport mode restrictions, and others (Jara-Diaz et al., 2008). These constraints significantly impact where and what activities individuals are able to pursue during their tourism trip. In fact, Lew and McKercher (2006) found that the principal way that individuals deal with these constraints is to combine more activities together. Rather than take separate trips with few unique activities, individuals will respond to constraints by merging activities together to facilitate participation in 
them. Moreover, Lew and McKercher (2006) determined that "time spent at a destination area is arguably the single most influential criterion shaping tourist behavior because it can directly constrain or expand the number and range of potential activities available and the depth at which individuals' activities can be experienced”. Third, in terms of travel motivation, individuals’ travel motivations such as enrichment, the ability to get away, and relaxing further encourage mixed activity participation (Dunn Ross and Iso-Ahola, 1991). Without required activities, such as work or errands, individuals are able to pursue many more different leisure activities that they normally would not be able to during typical daily life. In an effort to take advantage of this freedom and flexibility, individuals often select many different attractions and activities based on their interests and expectations (Hyde and Lawson, 2003).

In a sense, tourism activity participation can be interpreted as a highly specialized and social version of daily travel patterns. Larsen (2008) recognized that once tourists have arrived at their destination, they demonstrate activity scheduling not dissimilar from what they do on a daily basis, including an emphasis on combining trip activities. Hyde and Lawson (2003) also concluded that travelers tend to make their tourism activity decisions only for the immediate next 24-hour period, similar to daily travel. Still, the factors influencing these decisions are quite different from daily travel factors. Tourism travel is somewhat more specialized, meaning that individuals are typically focused on a set of relatively specific activities themed under a main purpose such as ecotourism, heritage tourism, recreational tourism, and exploratory tourism (Gibson and Yiannakis, 2002). Even within these main purposes, however, individuals seek variety in their activities which leads to combining of diverse activities. Social networks also play a much more significant role in tourism travel, as individuals often use long-distance travel to visit friends and family they only interact with virtually on a daily basis (Schlich et al., 2004). Therefore, individuals often pair their leisure activities with opportunities to meet or spend time with others. Despite the variety-seeking nature of activity participation in tourism trips, the tourism field has not seen the depth of study into activity combinations that is present in daily activity-travel participation (Ettema, 2005, Kapur and Bhat, 2007).

That is, of course, not to say that tourism researchers do not recognize the importance of studying combinations of activities during tourism-related travel. Indeed, many of the motivational theories developed to describe tourism behavior are explicitly built around individuals’ efforts to satisfy a variety of psychological needs (Gibson and Yiannakis, 2002). 
These theories, which include optimal arousal, recreation specialization, and activity and need theory, emphasize two important considerations: the value of time and the importance of novelty seeking. Time is a valuable resource for leisure travelers, and they schedule their time and activities to maximize their experience (Jara-Diaz et al., 2008). Optimal arousal theory, for example, states that individuals have many different motivations for making a tourism trip, and, as a result, they select a variety of leisure activities that provides the highest personal benefits (Dunn Ross and Iso-Ahola, 1991). Similarly, leisure travelers typically include activities that are out of the ordinary to make their trip memorable (Lee and Crompton, 1992). According to recreation specialization theory, as individuals become more skilled in specific types of activities, it is likely that they will narrow their activity participation to focus on finding something new within a set of related activities (Pearce and Lee, 2005). Combining multiple types of activities during a leisure trip supports both considerations. Furthermore, travelers' motivations and combinations of activities often change as they become more familiar with a destination. "When people make their first trip to a place, they tend to display more general interests, perhaps trying to experience and sample the whole country. In repeat visits, one's

interests become more focused on the specific types of activities and places, and activity participation is in more depth” Lehto et al. (2004).

In addition to the motivational theories proposed to describe participation in activity combinations during tourism travel, there have also been some application studies exploring the relationship between travel motivations and participation in activity combinations, mainly using the methods of cluster analysis or simple descriptive analysis. Earlier studies, classified in one of these two methods of analysis, are discussed in the subsequent two sections.

\subsection{Cluster Analysis-Based Studies}

The focus of cluster analysis-based studies has been to identify groups of individuals that have similar or dissimilar behaviors in combining activities (Hwang and Fesenmaier, 2003). One set of such studies clustered travelers based on their motivational factors affecting combined activity participation. Lee and Crompton (1992), for example, presented a literal interpretation of motivation, clustering individuals based on whether they were looking to combine activities themed around thrills, changes from routine, and others. Pearce and Lee (2005) studied how motivations change for individuals over travel careers, including relaxation, safety, relationships, 
self development, and self-actualization. Fennell (1996) undertook perhaps the most extensive study of combined activity motivation based on spatial patterns as well as level of interest. He identified travelers with a variety of spatial combinations of activities along with a variety of specialization in activities. A second set of studies, more relevant to the context of the current paper, clustered travelers based on the specific types of activities they combined. These studies looked at the combinations of activities individuals reported participating in during tourism travel, and developed clusters to describe common sets. Gibson and Yiannakis (2002) characterized travelers into fifteen unique groups that shared common activities themed around being outside, relaxing, sunbathing, sightseeing, etc. Similarly, Lehto et al. (2004) classified groups of travelers themed around nature appreciation, culture, shopping, tours, contrived entertainment, outdoor recreation, and sports. Hsieh et al. (1997) identified six interrelated groups of travelers that participated in different combinations of similar activities. He even classified some travelers as general tourists because they pursued too many different types of activities so they did not fit into any of the other specialized categories. In general, these results suggest that leisure travelers participate in combinations of activities that fit specific themes, indicative of the idea of recreational specialization. While all the clustering studies discussed above provide insights on individual groups who behave or who do not behave similarly in combining activities, they do not describe the factors that affect which specific activities or groups of activities an individual will participate in. As a result, they are not adequate for planners seeking predictive models of activity participation behavior during the tourism travel of individuals.

\subsection{Descriptive Analysis-Based Studies}

The focus of descriptive analysis-based studies has been more directly on the activities pursued by individuals and groups during tourism travel. Some of the most important factors include travel party composition and sociodemographics. For instance, the presence of children in the travel party leads to a higher inclination to participate in interactive or active activities, and to participate in a wide variety of activities (Nickerson and Jurowski, 2001). Older travelers have unique leisure activity participation trends as well; while older travelers tend to have less variety in tourism activities (Gibson and Yiannakis, 2002), they most often combine shopping with whatever other activities they are pursuing (Littrell et al., 2004). As one would expect, larger 
travel parties have been shown to be more likely to combine a wider variety of activities during tourism travel to accommodate the range of travelers' interests (Hwang and Fesenmaier, 2003). Additionally, one must consider the role that personal preferences and opinions have on what combinations of activities individuals will participate in. In fact, individuals' emotions and social expectations can be some of the most significant constraints for travelers (Dupuis, 2004). Of course, tourism behavior and activity participation naturally change over time as individuals grow, and heterogeneity of factors over lifecycles must be evaluated (Gibson and Yiannakis, 2002).

The descriptive analysis-based studies discussed above, while insightful from a general understanding of tourism travel perspective, are limited in their value as a predictive tool. Further, the descriptive analysis studies focus on broad main trip purposes, which describe the long-distance activity component of travel described above (see, for example, Gitelson and Kerstetter, 1990; Hsieh et al., 1997; Hwang and Fesenmaier, 2003; Hackney, 2004; Kemperman et al., 2006; Erhardt et al., 2007). Not surprisingly, there is even disagreement on how these broad main trip purposes should be defined to best describe the combinations of activities individuals pursue during a trip (e.g. 'visiting friends and family' versus 'social travel') (Kemperman et al., 2006).

This lack of research into combinations of activities during a tourism trip is primarily due to the fact that it is difficult to collect such detailed information on all the activities individuals pursue during a trip (Kuhimof and Wassmuth, 2002). It is far easier to ask respondents about the main trip purpose or to narrow in on a specific activity or site. As a result, all the combined types of activities pursued over an entire trip are summed up by a single trip purpose or by one independent activity. As Decrop and Snelders (2005), this translates into research that "assumes travelers' involvement in different activities is mutually exclusive." It is critical to bridge this gap between the main trip purpose collected from respondents and the actual specific activities in 
which they participated to enhance tourism demand modeling (Lutz et al., 2000; Kuhimof and Wassmuth, 2002). ${ }^{1}$

\section{THE NORTHWEST TERRITORIES EXIT SURVEY}

The data used in this study is drawn from the 2006 exit survey of visitors to the Northwest Territories (NWT) of Canada. Covering over 452,480 square miles, the NWT is recognized for its vast natural wilderness, its variety of outdoor adventure experiences, and its rich aboriginal culture. As such, tourism is a cornerstone of the territory's economy (Government of the NWT, 2009). In fact, "tourism currently contributes more than $\$ 133$ million in the economy of the Northwest Territories and generates more revenue than the combined revenue of all other renewable resources activities” (Outcrop, 2007). It is not surprising that over 28,000 travelers visited the NWT during the four months in which the exit survey was collected (NWT Tourism and Parks Division, 2007). While the NWT's Department of Industry, Tourism, and Investment recognizes that the most common reasons for visitors' long-distance, or long-haul, leisure travel to the NWT includes general touring, visiting friends and relatives, and outdoor adventure, they further acknowledge that these travelers “are active, looking for a 'suite of activities'. They are knowledgeable, experienced and they like having choices” (Outcrop, 2007).

With these travelers in mind, the department developed and collected surveys detailing the variety of activities in which visitors to the NWT participated (NWT Tourism and Parks Division, 2007). The NWT 2006 Visitor Exit Survey was distributed between May 15 and September 15, 2006, with visitors intercepted at visitor information centers (43.8\%), airports (40.8\%), and outfitters' lodges (15.4\%). Surveys collected at airports and outfitters' lodges were self-administered, while those collected at visitor information centers were completed via telephone interviews. One representative individual from each travel party was selected to complete each survey, so the information collected describes both that individual as well as their travel party. This information includes activity participation/ satisfaction, trip characteristics,

\footnotetext{
${ }^{1}$ Nowhere are the issues of planning for leisure activities more critical than in periphery or specialized tourist destinations. These areas are marketed based on their unique characteristics, such as their wilderness or cultural heritage, and decision-makers must be careful to develop such areas in ways that preserve these characteristics. As global tourism becomes more competitive, these areas are faced with difficult decisions regarding sustainability: should they diversify the types of activities at the destination or specialize in activities that emphasize their unique destination characteristics? Dupuis (2004) and Sung (2004) determined that both outdoor activity-oriented travelers as well as general tourists frequent these destinations, and it is critical for planners in these areas to understand which combinations of activities these types of travelers are most interested in pursuing while on vacation.
} 
travel party composition, traveler sociodemographics, general travel preferences, as well as other topics.

\subsection{Sample Formation}

The final data sample was assembled in a number of steps. First, the data from the three surveys (from the three different intercept locations) were standardized and merged together. Second, only those records associated with a main leisure trip purpose (such as general touring, outdoor activities, or visiting friends or relatives) were selected. Any records with a main trip purpose of business were removed. Third, those travel parties that spent more than 3 weeks in the NWT were removed. Fourth, those surveys that had missing or incomplete information, including the full descriptions of each member of the travel party, were removed. Finally, we had to identify the various activity types individuals participated in during their trip to NWT based on responses provided to satisfaction questions. The reason was that travel parties were not directly asked to report the activity types they participated in during the trip; rather, the survey was worded in such a way that respondents only responded to the satisfaction-related questions for activities specific to those that they undertook. Based on this translation from satisfaction responses to activity participation, we defined eight activity participation type variables: cultural activities (including arts or music festival, cultural event, or museum visit), touring activities (including airplane or helicopter, cruise, un/guided walking, or un/guided vehicle tours), shopping activities, sightseeing activities (including northern lights or historic site visits), wildlife experience activities (including bird, buffalo, or other wildlife viewing), land recreation activities (including bicycling, hiking, golfing, or camping), water recreation activities (including boating, rafting, canoeing, kayaking, or swimming), and hunting/fishing activities (including un/guided fishing or un/guided hunting). The final data sample comprises 734 records, each record detailing a travel party's trips to the NWT.

\subsection{Summary Statistics}

The resulting sample is reasonably representative of the types of travelers that visit the NWT. Of the three main trip purposes identified by the Department of Industry, Tourism, and Investment, general touring is by far the most common (59.4\%), with smaller percentages of travelers visiting friends or relatives (VFR) and seeking outdoor adventure (24.8\% and 15.8\%, respectively). 
Regardless of their main trip purpose, most travel parties are comprised of couples (48.8\%), followed by families (21.8\%), groups of friends (16.6\%), solo travelers (12.5\%), and very few traveling with co-workers (0.3\%). As one would expect based on the large number of couples and families traveling to the NWT, the majority of travel parties include adults aged 51 and older (68.1\%) and aged 31 to 50 (37.2\%). Families similarly tend to include older children and adults, with $42.8 \%$ of families comprised of only adults aged 21 years or older and $57.2 \%$ with one or more children aged less than 20 years old. Still, travel parties' incomes are well distributed between $\$ 30 \mathrm{k}$ and $100 \mathrm{k}$, with the majority of travelers falling in the $\$ 30-70 \mathrm{k}$ range (44.0\%). So, while costs may not limit people from visiting the NWT (as seen in the fact that travelers with many different incomes visit), longer travel times, the remoteness, and predominance of mature activities in the region may limit young families from visiting (as seen in the fact that fewer travel parties with children visit).

Due to the remoteness of the NWT, it is not surprising that $77.1 \%$ of the travel parties are from Canada, $17.7 \%$ of travel parties are from the United States, and the remaining 5.2\% of travel parties are from other countries. It is surprising, however, that two-thirds of the travelers in the sample are visiting the NWT for the first time. Additionally, the survey shows that firsttime visitors have slightly more initial travel concerns than those who have visited before: 93.3\% of first time visitors had over 10 concerns, whereas only $89.0 \%$ of repeat visitors had over 10 concerns. These different population groups will surely have different motivations for traveling to the NWT and will participate in different combinations of activities. In fact, of those who participated in the defined leisure activities in the previous section, $4.4 \%$ participated in all eight activities, $10.5 \%$ participated in seven activities, 22.8\% participated in six activities, 25.2\% participated in five activities, $17.1 \%$ participated in four activities, $11.2 \%$ participated in three activities, 6.1\% participated in two activities, and 2.7\% participated in just one activity. Table 1 further summarizes travel parties’ participation in specific combinations of activities. It should be noted that participation in these activities is not exclusive, as travel parties can participate in several combinations of activities. An important observation from Table 1 is that very few travel parties participated in a single activity type, as can be observed from the sparse percentage of the sample along the diagonal on Table 1 . The most common activity type combination pairs were sightseeing and wildlife experience activities (67.30\%), sightseeing and land recreation activities (62.67\%), wildlife experience and land recreation activities (58.99\%), touring and sightseeing 
activities (58.58\%), and shopping and sightseeing activities (57.63\%). The most common specific combinations were shopping/ sightseeing/ touring/ land recreation/ wildlife experience (4.1\%), shopping/ sightseeing/ land recreation/ wildlife experience (2.5\%), sightseeing/ touring/ land recreation/ wildlife experience (2.2\%), and shopping/ sightseeing/ touring/ land recreation $(2.0 \%)$.

\section{THE MULTIVARIATE BINARY PROBIT MODEL}

In this study, each travel party may participate in any combination of the eight leisure trip activities: cultural, touring, shopping, sightseeing, wildlife experience, land recreation, water recreation, and hunting/fishing. As such, the multivariate model system used in this study includes eight Binary Probit models, one model for the choice of participation in each specific activity. Additionally, correlation is added across outcomes to recognize the presence of unobserved travel group-related and contextual factors that may increase or decrease the propensity of participation in specific combinations of activity types.

The formulation for the multivariate model system follows the usual binary probit notation. Let $q$ be an index for travel party $q=(1,2, \ldots, Q)$, and let $i$ be an index for leisure activities ( $i=1,2, \ldots, I$; in the current empirical analysis, $I=8)$. In the usual utility maximizing postulate for discrete choice making, the latent propensity $\left(y_{q i}^{*}\right)$ of party $q$ selecting leisure activity $i$ may be written as the difference between the utilities of participation in activity $i\left(U_{q i}^{p}\right)$ non-participation in activity $i\left(U_{q i}^{n p}\right)$, which itself may be written as a linear function of relevant individual, trip, and preference variables:

$y_{q i}^{*}=U_{q i}^{p}-U_{q i}^{n p}=\beta_{i}^{\prime} x_{q i}+\varepsilon_{q i}$,

where $x_{q i}$ is a $(L \times 1)$ vector of exogenous variables, $\beta_{i}$ is a corresponding $(L \times 1)$ vector of coefficients that will be estimated, and $\varepsilon_{q i}$ is a standard normal error term assumed to be identically and independently distributed across parties. Of course, we do not observe the latent propensity $y_{q i}^{*}$. All that is observed in the estimation sample is whether party $q$ chooses to participate in activity $i$ or not; that is whether $y_{q i}=1$ (i.e., $y_{q i}^{*}>0$ ) or $y_{q i}=0$ (i.e., $y_{q i}^{*}<0$ ). If we ignore any association due to unobserved factors in the participation propensities across different 
activities $i$, the probability that party $q$ would participate in activity $i$ is simply the usual Binary Probit model:

$\operatorname{Prob}\left(y_{q i}=1\right)=\operatorname{Prob}\left(y_{q i}^{*}>0\right)=\Phi\left(\beta^{\prime} x_{q i}\right)$,

where $\Phi(.) Y_{q i}$ is the cumulative standard normal distribution operator. Similarly, the probability of non-participation is given by:

$\operatorname{Prob}\left(y_{q i}=0\right)=\operatorname{Prob}\left(y_{q i}^{*}<0\right)=\Phi\left(-\beta^{\prime} x_{q i}\right)$.

However, it is quite likely that there are common unobserved factors specific to a travel party that makes the party more or less likely to partake in certain combinations of activity types. For instance, a travel party that has an intrinsic propensity for physical activity and adventurism may be more inclined to participate in land recreation, water recreation, and wildlife experiences. In fact, earlier tourism-related studies suggest the strong presence of such unobserved factors in tourism-related choices (see Herriges et al., 2008). At the least, it behooves the analyst to consider such unobserved factor effects by accommodating correlations across activity types in the $\varepsilon_{q i}$ terms, and then testing for their absence. Accordingly, in the current study, we assume that the vector $\varepsilon_{q}=\left(\varepsilon_{q 1}, \varepsilon_{q 2}, \varepsilon_{q 3}, \ldots, \varepsilon_{q 1}\right)^{\prime}$ is multivariate normally distributed with a mean vector of zeros and a correlation matrix $\Omega$. That is,

$$
\varepsilon_{q} \sim N\left[\left\{\begin{array}{l}
0 \\
0 \\
\vdots \\
0
\end{array}\right\},\left\{\begin{array}{cccc}
1 & \rho_{12} & \cdots & \rho_{1 I} \\
\rho_{21} & 1 & \cdots & \rho_{2 I} \\
\vdots & \vdots & \ddots & \vdots \\
\rho_{I 1} & \rho_{I 2} & \cdots & 1
\end{array}\right\}\right] \quad \text { or } \quad \varepsilon_{q} \sim \operatorname{MVN}(0, \Omega) \text {. }
$$

The off-diagonal $\rho_{i j}$ terms of the correlation matrix $\Omega$ capture the impact that common unobserved factors have on the likelihood that individuals will participate in each pair of leisure activities during their tourism travel. Of course, if all these correlation parameters are identically zero, the multivariate model system presented here collapses to a series of independent Binary Probit models for each leisure activity. For notation purposes, let the off-diagonal terms of $\Omega$ be stacked vertically in a vector $\tilde{\Omega}$. The parameter vector of the multivariate probit model to be estimated is then $\delta=\left(\beta_{1}^{\prime}, \beta_{2}^{\prime}, \ldots \beta_{I}^{\prime}, \tilde{\Omega}^{\prime}\right)^{\prime}$. Additionally, we designate $m_{q i}\left(m_{q i} \in\{0,1\}\right)$ as the 
actual observed participation choice of individual $q$ in activity $i$. The classical likelihood function for individual $q$ can then be written as:

$$
\begin{aligned}
& L_{q}(\delta)=\operatorname{Pr}\left(y_{q 1}=m_{q 1}, y_{q 2}=m_{q 2}, \ldots, y_{q I}=m_{q I}\right) \\
& L_{q}(\delta)=\int_{v_{1}=\theta_{1}^{m_{q 1}-1}-\beta_{1}^{\prime} x_{q 1}}^{\theta_{1}^{m_{q 1}}-\beta_{1}^{\prime} x_{q 1}} \int_{v_{2}=\theta_{2}^{m_{q 2}-1}-\beta_{2}^{\prime} x_{q 2}}^{\theta_{q}^{m_{q 2}}-\beta_{2}^{\prime} x_{q 2}} \ldots \int_{v_{I}=\theta_{I}^{m_{q I}-1}-\beta_{I}^{\prime} x_{q I}}^{\theta_{I}^{m_{q I}}-\beta_{I}^{\prime} x_{q I}} \phi_{I}\left(v_{1}, v_{2}, \ldots, v_{I} \mid \Omega\right) d v_{1} d v_{2} \ldots d v_{I},
\end{aligned}
$$

where $\theta_{i}^{-1}=-\infty, \theta_{i}^{0}=0$, and $\theta_{i}^{1}=\infty$.

Unfortunately, the likelihood function above is rather complex and requires the computation of an 8-dimensional normal orthant integral. In the past, Maximum simulated Likelihood and Bayesian Markov Chain Monte Carlo methods would have been traditionally used to solve for the parameters (see Bhat and Srinivasan, 2005, and Herriges et al., 2008). However, while these methods are able to evaluate multidimensional normal integrals, they have been shown to be computational taxing, require extensive simulation, and are time-consuming. Even more important, these methods often can be imprecise and suffer from convergence issues (Ferdous et al., 2010). Instead, this study uses the pairwise Composite Marginal Likelihood (CML) function (Lindsay, 1988, Varin, 2008) for each individual (q), which can be written as:

$$
\begin{aligned}
& L_{C M L, q}(\delta)=\prod_{i=1}^{I-1} \prod_{g=i+1}^{I} \operatorname{Pr}\left(y_{q i}=m_{q i}, y_{q g}=m_{q g}\right) \\
& =\prod_{i=1}^{I-1} \prod_{g=i+1}^{I}\left[\begin{array}{c}
\Phi_{2}\left(\theta_{i}^{m_{q i}}-\beta_{i}^{\prime} X_{q i}, \theta_{g}^{m_{q g}}-\beta_{g}^{\prime} x_{q g}, \rho_{i g}\right)-\Phi_{2}\left(\theta_{i}^{m_{q i}}-\beta_{i}^{\prime} x_{q i}, \theta_{g}^{m_{q g}-1}-\beta_{g}^{\prime} x_{q g}, \rho_{i g}\right) \\
-\Phi_{2}\left(\theta_{i}^{m_{q i}-1}-\beta_{i}^{\prime} x_{q i}, \theta_{g}^{m_{q g}}-\beta_{g}^{\prime} x_{q g}, \rho_{i g}\right)+\Phi_{2}\left(\theta_{i}^{m_{q i}-1}-\beta_{i}^{\prime} x_{q i}, \theta_{g}^{m_{q g}-1}-\beta_{g}^{\prime} x_{q g}, \rho_{i g}\right)
\end{array}\right),
\end{aligned}
$$

which combines to:

$$
L_{C M L}(\delta)=\prod_{q} L_{C M L, q}(\delta)
$$

The CML method is an emerging inference approach in the statistics field, though there has been little to no coverage of this method in the econometric and other fields (see Varin and Vidoni, 2009, Bhat et al., 2009, 2010). In general, the CML method considers pairs of observations, hence the term pairwise likelihood. As Equation (6) demonstrates, the CML method develops a surrogate likelihood function by calculating likelihoods for each pair of leisure activities and combining these marginal likelihood objects. Thus, the CML method removes the need to evaluate the large dimensional orthant integral one would typically need to 
do with classical maximum likelihood. The CML estimator $\hat{\delta}_{C M L}$ obtained by maximizing the logarithm of the CML function in Equation (6) is consistent and asymptotically normal distributed (this is because of the unbiasedness of the CML score function, which is a linear combination of proper score functions associated with the marginal event probabilities forming the composite likelihood). Specifically, the estimator is asymptotically normal distributed with asymptotic mean $\delta$ and covariance matrix given by the inverse of Godambe's (1960) sandwich information matrix $G(\delta)$ (see Zhao and Joe, 2005):

$$
\begin{aligned}
& V_{C M L}(\delta)=[G(\delta)]^{-1}=[H(\delta)]^{-1} J(\delta)[H(\delta)]^{-1} \text {, where } \\
& H(\delta)=E\left[-\frac{\partial^{2} \log L_{C M L}(\delta)}{\partial \delta \partial \delta^{\prime}}\right] \text { and } \\
& J(\delta)=E\left[\left(\frac{\partial \log L_{C M L}(\delta)}{\partial \delta}\right)\left(\frac{\partial \log L_{C M L}(\delta)}{\partial \delta^{\prime}}\right)\right]
\end{aligned}
$$

$H(\delta)$ and $J(\delta)$ can be estimated in a straightforward manner at the CML estimate $\left(\hat{\delta}_{C M L}\right)$ :

$$
\begin{aligned}
\hat{H}(\hat{\delta}) & =-\left[\sum_{q=1}^{Q} \frac{\partial^{2} \log L_{C M L, q}(\delta)}{\partial \delta \partial \delta^{\prime}}\right]_{\hat{\delta}} \\
& =-\left[\sum_{q=1}^{Q} \sum_{i=1}^{I-1} \sum_{g=i+1}^{I} \frac{\partial^{2} \log \operatorname{Pr}\left(y_{q i}=m_{q i}, y_{q g}=m_{q g}\right)}{\partial \delta \partial \delta^{\prime}}\right]_{\hat{\delta}}, \text { and } \\
\hat{J}(\hat{\delta}) & =\sum_{q=1}^{Q}\left[\left(\frac{\partial \log L_{C M L, q}(\delta)}{\partial \delta}\right)\left(\frac{\partial \log L_{C M L, q}(\delta)}{\partial \delta^{\prime}}\right)\right]_{\hat{\delta}}
\end{aligned}
$$

\section{EMPIRICAL ANALYSIS}

Several types of variables were considered in the model specification. These included trip characteristics, travel party composition, traveler sociodemographics, as well as preferences and concerns. The final model specification, presented in Table 2, was arrived at by systematically removing statistically insignificant variables and combining variables when their effects were statistically similar. Due to the fact that the survey was completed by a single representative 
person from each travel party, the results are discussed in terms of both travel parties' and individuals’ behavior, as appropriate.

It is important to note that travelers are not selecting between the eight leisure activities listed in Table 2. Rather, the table summarizes the effects of variables on the latent underlying propensity of participation in each of the eight leisure activities. For example, a positive coefficient in touring activities and a negative coefficient in shopping activities do not mean that the traveler prefers touring over shopping (as would be the case in a multinomial choice model), but s/he is simply more likely to make a touring activity and less likely to make a shopping activity. Table 3 further details the correlation matrix of activity participation combinations.

\subsection{Trip Characteristics}

The first category of variables considers the trip characteristics that broadly define travel goals and defining details. These factors, which include main trip purposes, travelers' first visits, the country of origin, travel mode, and trip extent, succinctly describe the broad structure of leisure trips. As such, researchers and practitioners consistently rely on them when studying or planning for tourism travel. Not surprisingly, the estimation results show that these factors play a significant role in determining the activities in which individuals participate during tourism travel.

Travelers were first asked to classify the main purpose of their trip as general touring, outdoor activities, or visiting friends and relatives. Those traveling for the main purpose of pursuing outdoor activities are more likely to pursue combinations of water recreation and hunting/ fishing activities and less likely to include cultural, touring, shopping, or sightseeing activities, relative to those traveling for general touring. Similarly, those traveling for the main purpose of visiting friends or relatives are more likely to undertake combinations of water recreation and hunting/ fishing activities and less likely to include cultural, touring, or sightseeing activities, relative to those traveling for general touring. These two main trip purposes tend to indicate a level of experience with or knowledge of the NWT, so it would then follow that people traveling for these purposes are less likely to participate in combinations of typical tourist activities.

Likewise, new visitors are most likely to participate in combinations of touring, shopping, and sightseeing activities, relative to those travelers who have visited the NWT 
territories previously. This is consistent with the understanding that 'touristy' activities, such as touring, shopping, and sightseeing, are typically the first things visitors will pursue when they arrive at a destination for the first time. Once they become familiar with the geography and culture, they will move on to more specific activities matched to their particular interests.

Interestingly, activity participation varies significantly by where travelers are from. For example, Canadians traveling to the NWT are not as interested in wildlife, but are more interested in water recreation activities, relative to travelers from other countries. US travelers are also less interested in combining wildlife and shopping activities with their other leisure activities. Perhaps experiencing wildlife and shopping is not as interesting to Canadians and Americans as they are to non-North Americans, since North Americans perhaps participate in these familiar activities on a daily basis.

Travel modes and trip extents, which are essentially extensions of where travelers are from, also affect the activities in which travelers participate. Those traveling by air (i.e. individuals who traveled a long distance) are more likely to pursue combinations of touring and water recreation activities, relative to those who drove to the NWT. They are also less likely to combine sightseeing, shopping, wildlife, and land recreation activities during their trip. Alternatively, if this trip to the NWT is part of a longer tour of Canada, individuals are more likely to combine cultural, sightseeing, and wildlife experience activities on their trip. These results indicate that those individuals coming to the NWT from farther away or spending longer times in Canada are more interested in combining activities that immerse themselves in the culture, whether it be by an organized tour or through personal discovery.

\subsection{Travel Party Composition}

Travel party composition plays a significant role in influencing which activities the party participates in. In fact, individuals rarely make leisure travel decisions independent of their travel party. Even if individuals in a travel party don't participate in all activities together, their activity selections are made relative to each other. This section will discuss the impact that travel party type, number of children, and number of adults have on both individual and travel parties’ leisure activity participation.

Travel parties can be classified in a number of ways, including traveling alone, as a couple, with family, with friends, and with co-workers. The estimation results show a general 
trend, relative to traveling alone, that the more close-knit a travel party is, the more likely that individuals in the travel party will be to freely explore an area through a wider array of activities. Alternatively, the less cohesive the group, the more likely individuals in the party are to participate in specifically defined activities of a shared interest. For example, couples are more likely to pursue combinations of cultural, shopping, and land recreation activities. Families are also more likely to participate in combinations of cultural, shopping, sightseeing and hunting/fishing activities. Groups of friends typically participate in combinations of cultural activities and hunting/fishing. Finally, co-workers tend to exclusively hunt and/or fish while in the NWT. It is not surprising to see that all travel party types, besides traveling alone or as a couple, participate in hunting/fishing, as this is a main draw of the NWT.

The transportation and leisure literature unanimously recognizes that children play an extremely important role in how families spend their time. In terms of tourism travel to the NWT, travel parties with children seem to emphasize outdoor activities that are engaging for children and take advantage of the unique draw of the area, including combinations of wildlife experiences, land recreation, water recreation, and hunting/fishing. As children get older, travel parties are more likely to focus on combining water recreation and wildlife activities. On the other hand, the results indicate that it is the travel parties with extremely young children (i.e. young families) that are most likely to participate in hunting/fishing activities.

Additionally, travelers' leisure activity participation trends shift as they age. Travel parties with more young adults (i.e. aged 21 to 30) are more likely to remain physically active during tourism travel combining touring, wildlife, and land and water recreation activities while excluding sightseeing and cultural activities. Adults aged 31 to 50 have the broadest leisure activity interests. While they prefer similar combinations of touring, wildlife, and land and water recreation activities, they do not demonstrate a distinct disinterest in cultural or sightseeing activities. Finally, travel parties with older adults (aged 51 or older) prefer less physical activities, tending to combine cultural, wildlife viewing, and water recreation activities on tourism trips.

\subsection{Traveler Sociodemographics}

The NWT exit survey collected minimal information about individuals’ sociodemographics. Of the variables considered, only individuals' education and annual income were significant. While 
these variables exclusively describe each survey respondent, they can also be assumed to represent the group with which he/she is traveling.

First, the estimation results, not surprisingly, indicate that the more educated the representative traveler is, the more his or her party will appreciate cultural activities and have an understanding of the local sights. As a result, his or her party would be more likely to combine these activities on their trip to the NWT. Specifically, as the representative individuals' education increases past high school, the more interested the party becomes in combining cultural and sightseeing activities during their trip as well as relatively less interested in hunting/ fishing activities. Additionally, college graduates are more likely to include water recreation activities on their trip. High school-educated travelers are also less likely to include shopping as part of their trip.

The estimation results further indicate that the travel parties whose representative individual has a higher income are more likely to hunt and fish, to the exclusion of cultural, touring, and shopping activities. While this behavior may seem counter intuitive, it is actually an excellent example of outdoor recreation specialization. The results demonstrate how travel parties selected this region specifically because they are able to participate in the outdoor adventure activities for which the region is known. Specialized travelers, such as these, are most likely skilled in hunting and fishing to the point where much of their leisure time is spent enjoying or improving these skills. As such, they are not interested in spending their leisure time pursuing general tourist activities in the NWT. The reason this specialization appears for higher income levels is because they can afford to tailor their trips to (often more expensive) destinations that are specifically oriented toward their particular interests or skills.

\subsection{Preferences and Concerns}

The final category of variables is the most insightful in terms of capturing travelers' underlying preferences and concerns. Again, these preferences and concerns were elicited only from the representative individual of each travel party, but should characterize the overall preferences and concerns of all travelers in the travel party. These preference/concern factors can play a large role in determining travelers' destination selection, emotional attachment, and ultimate activity participation. In the survey, respondents used a likert-scale to rank a variety of factors on how important a consideration each factor was to this trip. These scales were then recoded as an 
important consideration if the representative respondent of the travel party scored that variable in the upper half of the likert-scale. As such, respondents could identify any combination of factors as important. The following series of preference factors are grouped into 8 categories that describe common concerns, including costs, personal experience, high quality accommodations, entertainment, shopping, touring, nature, and climate.

One of the most common concerns when planning tourism travel is that of cost. In this study, travelers were asked about two specific cost concerns: the cost of accommodations and meals as well as the cost of travel to the destination. Interestingly, these types of cost concerns highlight two types of travelers. Those concerned with the cost of accommodations and meals are travelers who are intrinsically enthusiastic about a destination and are, thus, unconcerned with the cost to get there. However, they need to remain frugal once they arrive. Still, as the model estimation shows, these travelers are keen to participate in combinations of destinationspecific cultural and land recreation activities. Those concerned with the cost of travel to the destination, on the other hand, represent travelers who are selecting a destination based on where they can afford to travel. Interestingly, these travelers tend to exclusively participate in sightseeing activities as well as purposely avoid wildlife experience activities during tourism travel.

Many tourism travelers seek some level of personal development or enrichment as part of their tourism trip. Still, individuals' definition of this personal development can vary greatly. The model estimation identified two distinct interpretations: those who actively seek out challenges and those who actively seek to immerse themselves in cultural explorations. The first group of travelers, who identified personal challenges or physical adventure as important to the trip, tended to combine physically taxing activities together. Those travelers who prefer personal challenges are significantly less likely to combine more traditional touring, shopping and water recreation activities. Similarly, travelers who prefer physical adventure pursue combinations of adventurous touring, wildlife, land and water recreation activities while on their trip. Alternatively, the second group of travelers, who identified meeting new people, unique cultural experiences, and learning opportunities as important to the trip, was more interested in challenging themselves psychologically. Travelers who prefer meeting new people tend to exclusively combine cultural and touring activities. Those that prefer unique cultural experiences are significantly more likely to exclusively pair sightseeing and land recreation 
activities. Finally, travelers who enjoy learning opportunities during tourism travel typically combine touring, shopping and water recreation activities. Interestingly, the combination of activities preferred by these travelers is the complete opposite of those who stated that personal challenges are most important.

Others are especially concerned about the quality of their accommodations. In general, those travelers who indicated that high quality accommodations are important to their leisure travel are significantly more likely to avoid combinations of activities that involve outdoor physical activities and are more likely to pursue combinations of relaxing (and more expensive) activities. As such, one would expect these travelers to also have higher individual incomes. Those travelers who stated that luxurious accommodations are especially important for their trip are the most representative of this category, as they strongly avoid any combination of touring, shopping, wildlife, land recreation, and water recreation activities. These results support individuals' interest in enjoying and relaxing at their accommodations. Travelers most concerned with cleanliness and hygiene are less likely to participate in land recreation activities such as overnight camping. A common concern for tourism travel is safety, and those who ranked it as important naturally prefer combinations of touring and water recreation activities, both of which can be characterized by contained and controlled environments.

Again, the estimation results reveal that travelers define concerns about entertainment in a variety of ways, including three specific types defined by the survey: having a relaxing break from work, general fun, and exciting nightlife. Travelers who are looking for a relaxing break from work tend to combine shopping and land recreation activities while avoiding touring activities. Touring activities can be restricting with set times and schedules, so those people trying to take a break from daily restrictions would naturally tend to stay away from those activities. Travelers for whom "having fun" is an important part of their trip tend to exclusively participate in hunting/fishing activities. Additionally, these travelers are less likely to combine shopping, wildlife, and land recreation activities. The final type of entertainment centers around nightlife, and travelers who look forward to this type of entertainment tend to combine touring and shopping leisure activities.

As one might expect, those travelers who report that shopping is an important part of their tourism travel are highly likely to shop during a trip. Additionally, these travelers typically combine their shopping activities with sightseeing activities as well as avoid physical land 
recreation activities. Furthermore, a unique subset of shopper tourists is concerned with having opportunities to purchase local crafts and art. These travelers additionally combine wildlife activities with their shopping and sightseeing activities. Predictably, a significant number of the shopping-oriented travelers are also specifically concerned about the quality of their accommodations.

Tours are a popular way for travelers to get to see areas or participate in activities that they normally would not know about or feel comfortable doing on their own. The results indicate that travelers who prefer complete package tours tend to be less adventurous in their activity pursuits, while those who prefer small organized tours at destinations tend to be more adventurous. The first group is significantly less likely to participate in combinations of shopping, sightseeing, and land recreation activities (most probably because their tour dictates in which activities they participate). The second group, however, is much more likely to participate in touring, shopping, sightseeing, wildlife, and land recreation activities. These travelers are able to go to destinations, pick their activities, and select the tours that meet their interests.

The final two areas of preferences/concerns deal with nature and climate of the destination. Travelers who are focused on nature are generally more likely to combine naturebased activities during their trip. Specifically, if outstanding scenery, viewing wildlife and parks and wilderness areas are important, travelers will commonly combine cultural, touring, wildlife, and land recreation activities to some degree. Likewise, if travelers stated climate as being especially important, they are more likely to pursue outdoor activities. Some travelers who are looking for warm, sunny climates tend to exclusively pursue land recreation activities. Others who are looking for reliable weather when selecting a tourism destination are more likely to combine shopping and wildlife viewing activities.

\subsection{Correlation}

The estimated covariances and their t-statistics are shown in Table 3. These correlation values provide the dependence between the underlying propensities $Y_{q i}^{*}$ due to unobserved factors. Positive values of the correlation for two activities $i$ and $g$ indicate that the two activities are more likely to be undertaken together, due to unobserved variables. Negative values of the correlation for two activities $i$ and $g$ indicate that the two variables are not likely to be 
undertaken together, due to unobserved variables. As one would expect, the table is symmetric along the diagonal.

The correlation results are interesting for a number of reasons. First, the large number of significant and consistently positive values within the table suggests that there are many unobserved factors that are affecting participation in combinations of activities. This supports the previous literature findings that travelers have an inherent desire (due to factors unobservable to the analyst) to combine a variety of activities during leisure trips. In the rest of this section, we will use the wording "more likely" and "less likely" to describe participation in two activities, though it should be kept in mind is that these tendencies are based on factors unobserved to the analyst (that is after controlling for all the observed variables). The results suggest that if travelers are more likely to participate in sightseeing activities, they are inherently more likely to combine those activities with touring. Second, the largest correlation values appear between shopping and sightseeing activities (0.544) as well as between wildlife and land recreation activities (0.402). This indicates that, of all the different combinations of activities in which travelers participate, they are mostly likely to pair shopping and sightseeing, and wildlife and land recreation activities. Third, the shaded regions of Table 3 highlight the two distinct groups of commonly combined activities. These fully-correlated groupings capture complete sets of unobserved factors that cause travelers to package activities together. The first group (outlined in dashes) draws attention to the behavior of general tourist travelers. Most general tourists tend to combine touring, shopping, sightseeing, wildlife experience, and land recreation activities together. The second group (outlined in double-dashes) captures dedicated outdoor travelers' behavior. As the grouping suggests, these travelers are looking for experiencing physical outdoor activities, and tend to group together wildlife experience, land recreation and water recreation activities together on their trip. If a traveler is looking to spend time outdoors in the NWT, they will naturally fall into this group of activities. Fourth, the fact that cultural and hunting/fishing leisure activities fall outside of the shaded regions emphasizes that travelers tend to dedicate their trips to these unique activities, rather than pair them with many other activities. The correlation results suggest that cultural and hunting/fishing activities are specialized, and visitors who travel to the NWT to participate in these activities are being drawn there specifically for those specialized opportunities. Finally, it is important to recognize that no matter what activities travelers pursue on their trip, they have a highly (statistically) significant propensity to 
combine these activities with wildlife experience and land recreation. This is not surprising as wildlife experience and land recreation activities cover the widest range of pursuits and are integral to the NWT experience.

\subsection{Likelihood-Based Measure of Fit}

The log-likelihood of the final model is -20639.8. The corresponding value for model with only the constants and no error components is -23882.2. The likelihood ratio test for testing the presence of exogenous variable effects and the presence of error components is 6484.8, which is substantially larger than the critical chi-square value with 65 degrees of freedom at any reasonable level of significance (the 65 degrees of freedom in the test represents the 48 distinct parameters on exogenous variables estimated in the final specification plus the 17 error components). Additionally, the log-likelihood for the final model without correlation parameters is -20718.6. The likelihood ratio test to determine the significance of these error components is 157.6, which is also noticeably larger than the critical chi-squared value with 17 degrees of freedom at any reasonable level of significance. This clearly indicates the value of the model estimated in this paper to predict individuals' combined activity participation based on trip characteristics, travel party composition, traveler sociodemographics, and preferences or concerns.

\section{CONCLUSIONS}

Over the past decade, the number of national and international long-distance leisure (i.e. tourism) trips has dramatically increased. In response, planners and officials have begun to recognize the marked impact this type of travel has on local and regional economies, congestion, and growth. To better anticipate these impacts, planners are turning to predictive models that incorporate travel behavior. These models are responsive to policy, development, and planning factors, which allow practitioners to more accurately and effectively predict how changes will affect regional sustainability and growth. A significant component of these travel behavior models is understanding the combinations of activities in which tourists participate. Unfortunately, most of the previous work on leisure activities is based on descriptive analyses, and is split between focusing on broad trip purposes on the one hand and only considering a single activity from the 
overall trip on the other. As such, while insightful, these earlier studies are limited in their ability to predict tourism behavior.

The current study addresses this gap in knowledge by modeling travelers' participation in any combination of eight leisure trip activities: cultural, touring, shopping, sightseeing, wildlife experience, land recreation, water recreation, and hunting/fishing. The analysis utilizes activity participation data from a tourist exit survey collected from the Northwest Territories (NWT) in Canada. A Multivariate Binary Probit model system, with correlation across every pair of leisure activities, is employed in the empirical analysis. This model is efficiently estimated using a Composite Marginal Likelihood method, which develops a surrogate likelihood function by computing likelihoods for each pair of leisure activities and combining these marginal likelihood objects.

The empirical analysis results emphasize that travelers quite often combine specific sets of leisure activities together during tourism travel. However, which sets of activities get paired together depends greatly on travelers' experience, travel companions, and individual concerns. As one would expect, travelers' experience with a destination, region, or culture plays an extremely significant role in what activities are combined during their trip. The more familiar a traveler is with the destination, the more likely the traveler is to focus on combining unique activities available at the tourism destination. On the other hand, less experienced and first time visitors will likely stick to combinations of typical tourist activities, such as sightseeing and touring. The results further indicate that those tourists visiting the NWT from farther away or spending longer times in Canada are more interested in combining activities oriented toward cultural discovery, whether it be through an organized tour or through personal discovery. Additionally, travel party composition greatly affects the combinations of activities in which the party participates. For example, the more close-knit a travel party is, the more likely they are to combine a wider variety of activities, from touring to water recreation. Alternatively, the less cohesive the group, the more likely they are to combine only a few, strictly event-focused activities of shared interest during their trip. Naturally, specific travel parties with children or that are generally younger are more likely to pursue combinations of physically active activities. Moreover, one cannot underestimate the importance of travelers' perceptions, concerns and expectations on activity participation. There are many layers and depth to the way people think 
about various issues (especially costs, personal experiences, and touring) that can influence the combinations of activities they pursue during tourism travel.

The correlation results further highlight travelers' inherent need to combine various activities during tourism trips. Most notably, two distinct groups of commonly combined activities were identified. The first group captures general tourist behavior, and shows that these travelers tend to combine touring, shopping, sightseeing, wildlife experience, and land recreation activities together. The second group captures dedicated outdoor traveler behavior. As the grouping suggests, these travelers are looking for experiencing physical outdoor activities, and tend to group together wildlife experience, land recreation and water recreation activities together on their trip. Two unique activities, cultural and hunting/fishing, fell outside of these groups and are rarely paired with other activities. This suggests that cultural and hunting/fishing activities are specialized, and individuals traveling to the NWT to participate in these activities are being drawn there specifically for those specialized opportunities.

Overall, these findings support the theories of recreation specialization and optimal arousal. Recreation specialization states that the more skilled travelers become with a specific leisure activity, the more likely they are to focus their trips around those activities. Additionally, optimal arousal asserts individuals' need to participate in a variety of activities. While some may argue that these are conflicting ideologies, the results from this study support both. First time and less experienced travelers tend to participate in a variety of activity types. They attempt to get the most out of their trip, rather than narrow in on a few specific activities. On the other hand, the experienced dedicated outdoor travelers (who also overlap with those traveling with co-workers and friends) focus their activity participation on a specific set of activities. Still, it is important to recognize that these travelers include a combination of activities in their trip; it just happens to be a much more precise set of activities based around their skills (e.g. hunting/fishing, cultural, or outdoor recreational activities). No matter what activities travelers are orienting their trip around, they will most likely allow time for additional complementary activities.

These results have a number of implications for tourism planning and demand modeling. Planners are concerned with both retaining current visitors as well as attracting new ones. In order to develop an area that supports both, a destination needs to include a variety of basic tourist activities as well as identify specific areas that support unique sets of activities. New visitors will be drawn by the offer of familiar combinations of tourist activities, but will then 
continue to return to participate in the sets of uniquely specific activities. The NWT are so successful in that they are able to support both travelers going away for a general break as well as those specifically oriented towards outdoor physical activities.

In terms of tourism demand modeling, researchers often focus on travelers' main trip purposes. However, results from this study show that while this information is useful in practice, it only provides partial trip information and should not be considered alone. Leisure trips especially are rarely comprised of a single activity, and the empirical findings suggest that the main trip purpose labels are actually useful in determining the combination of activities an individual will pursue. For example, those traveling to visit family/friends or for outdoor activities demonstrate a certain level of familiarity with the NWT and, as such, are less likely to participate in combinations of typical tourist activities (relative to those traveling for just general touring). As a result, researchers and planners need to consider combined activities more explicitly beyond main trip purposes when forecasting leisure travel demand.

Of course, there are many opportunities for future research on this topic. First, it would be useful to confirm whether the conclusions from the NWT data can be generalized to other regions. Admittedly, the NWT can be considered a specialized destination, and the results of the impacts of factors may be quite different for other tourism destinations. Second, it would also be interesting to further explore the travel context of combined activity participation. Does the spatial travel context affect what activities a traveler is able to combine during a leisure trip? This study focuses on just leisure activities, but it can be common for travelers to combine work and leisure on longer trips. Therefore, it would be useful to extend the analysis to include work trips during tourism travel. Third, alternative structures to the multivariate probit model may be considered to model participation in leisure activities. Finally, the results associated with traveler preferences and attitudes highlight the importance of continuing to explore such non-traditional factors within the context of travel demand modeling.

\section{ACKNOWLEDGEMENTS}

The authors are grateful to Lisa Macias for her help in typesetting and formatting this document. Three reviewers provided useful comments on an earlier version of this paper. 


\section{REFERENCES}

Bhat, C.R. and Srinivasan, S. (2005). A multidimensional mixed ordered-response model for analyzing weekend activity participation. Transportation Research Part B 39(3), 255278.

Bhat, C.R., Sen, S., and Eluru, N. (2009). The impact of demographics, built environment attributes, vehicle characteristics, and gasoline prices on household vehicle holdings and use. Transportation Research Part B 43(1), 1-18.

Bhat, C.R., Sener, I.N., and Eluru, N. (2010). A flexible spatially dependent discrete choice model: formulation and application to teenagers' weekday recreational activity participation. Transportation Research Part B 44(8-9), 903-921.

Decrop, A. and Snelders, D. (2005). A grounded typology of vacation decision-making. Tourism Management 26, 121-132.

Dunn Ross, E.L. and Iso-Ahola, S.E. (1991). Sightseeing tourists' motivation and satisfaction. Annals of Tourism Research 18, 226-237.

Dupuis, L. (2004) Winter tourism in protected pleasure peripheries: time-space use among crosscountry skiers in Abisko (Sweden) and Vercors (France). Scandinavian Journal of Hospitality and Tourism 4(2), 129-153.

Erhardt, G.D., Freedman, J., Stryker, A., Fujioka, H., and Anderson, R. (2007). Ohio longdistance travel model. Transportation Research Record 2003, 130-138.

Ettema, D. (2005). Latent activities: modeling the relationship between travel times. Transportation Research Record 1926, 171-180.

Fennell, D.A. (1996). A tourist space-time budget in the Shetland Islands. Annals of Tourism Research 23(4), 811-829.

Ferdous, N., Pinjari, A.R., Bhat, C.R., and Pendyala, R.M. (2010). A comprehensive analysis of household transportation expenditures relative to other goods and services: an application to United States consumer expenditure data. Transportation 37(3), 363-390.

Gibson, H. and Yiannakis, A. (2002). Tourist roles: needs and the lifecourse. Annals of Tourism Research 29(2), 358-383.

Gitelson, R.J. and Kerstetter, D.L. (1990). The relationship between sociodemographic variables, benefits sought and subsequent vacation behavior: a case study. Journal of Travel Research 28, 24-29.

Godambe, V. (1960). An optimum property of regular maximum likelihood equation. Annals of Mathematical Statistics 31, 1208-1211.

Government of the NWT. (2009). Facts about the NWT. Accessed from: http://www.gov.nt.ca/research/facts/

Hackney, J. (2004). Discrete choice models for long-distance travel based on the DATELINE survey. $4^{\text {th }}$ Swiss Transport Research Conference, Monte Verita/Ascona, March 25-26, 2004. 
Hellstrom, J. (2006). A bivariate count data model for household tourism demand. Journal of Applied Economics, 21, 213-226.

Herriges, J.A. and Phaneuf, D.J. (2000). Controlling for correlation across choice occasions and sites in a repeated mixed logit model of recreation demand. Technical Paper, Iowa State University.

Herriges, J.A., Phaneuf, D.J., and Tobias, J.L. (2008). Estimating demand systems when outcomes are correlated counts. Journal of Econometrics 147, 282-298.

Hsieh, S., O’Leary, J.T., Morrison, A.M., and Chlang, D. (1997) Travel decision pattern segmentation of pleasure travel. Journal of Vacation Marketing 3(4), 289-302.

Hwang, Y. and Fesenmaier, D.R. (2003). Multidestination pleasure travel patterns: empirical evidence from the American Travel Survey. Journal of Travel Research 42, 166-171.

Hyde, K.F. and Lawson, R. (2003). The nature of independent travel. Journal of Travel Research 42, 13-23.

Jara-Diaz, S.R., Munizaga, M.A., Greeven, P., Guerra, R., and Axhausen, K. (2008). Estimating the value of leisure from a time allocation model. Transportation Research Part B 42(10), 946-957.

Kapur, A. and Bhat, C.R. (2007). On modeling adults' daily time use by activity purpose and accompaniment arrangement. Transportation Research Record 2021, 18-27.

Kemperman, A.D.A.M., Ponje, M.M.W., and Timmermans, J.J.P. (2006). Analyzing heterogeneity and substitution in trip making propensity to urban parks: a mixed logit model. Tourism Analysis 10, 223-232.

Kuhimof, T. and Wassmuth, V. (2002). Do you go to the movies during your lunch break: tripcontext data-based modeling of activities. Transportation Research Record 1807, 34-42.

LaMondia, J. and Bhat, C.R. (2010). A conceptual and methodological framework of leisure activity loyalty accommodating the travel context: application of a copula-based bivariate ordered-response choice model. Technical paper, Department of Civil, Architectural and Environmental Engineering, The University of Texas at Austin.

Larsen, J. (2008). De-exoticizing leisure travel. Leisure Studies 27(1), 21-34.

Lee, T. and Crompton, J. (1992). Measuring novelty seeking in tourism. Annals of Tourism Research 19, 732-751.

Lehto, X.Y., O’Leary, J.T., and Morrison, A.M. (2004). The effect of prior experience on vacation behavior. Annals of Tourism Research 31(4), 801-818.

Lew, A. and McKercher, B. (2006). Modeling tourist movements: a local destination analysis. Annals of Tourism Research 33(2), 403-423.

Lindsay, B.G. (1988). Composite likelihood methods. Contemporary Mathematics 80, 221-239.

Littrell, M.A., Paige, R.C., and Song, K. (2004). Senior travelers: tourism activities and shopping behaviours. Journal of Vacation Marketing 10(4), 348-362.

Lutz, J., Englin, J., and Shonkwiler, J.S. (2000). On the aggregate value of recreational activities. Environmental and Resource Economics 15, 217-226. 
Nickerson, N.P. and Jurowski, C. (2001). The influence of children on vacation travel patterns. Journal of Vacation Marketing 7, 19-30.

NWT Tourism and Parks Division. (2007). Northwest Territories: 2006 Visitor Exit Survey Summary Report. Report for the Government of the NWT, Department of Industry, Tourism, and Investment.

Outcrop. (2007). Strategic Overview of Current and Potential Visitor Markets of the Northwest Territories. Report prepared for the Northwest Territories. December.

Pearce, P.L. and Lee, U. (2005). Developing the travel career approach to tourist motivation. Journal of Travel Research 43, 226-237.

Schlich, R., Schonfelder, S., Hanson, S., and Axhausen, K.W. (2004). Structures of leisure travel: temporal and spatial variability. Transport Reviews 24(2), 219-237, March.

Simma, A., Schlich, R., and Axhausen, K.W. (2002). Destination choice modelling for different leisure activities. Arbeitsberichte Verkehrs- und Raumplanung, 99, Institut für Verkehrsplanung und Transporttechnik, Strassen- und Eisenbahnbau, ETH Zürich, Zürich.

Sung, H.H. (2004). Classification of adventure travelers: behavior, decision making, and target markets. Journal of Travel Research 42, 343-356.

Varin, C. (2008). On composite marginal likelihoods. Advances in Statistical Analysis 92(1), 128.

Varin, C. and Vidoni, P. (2009). Pairwise likelihood inference for general state space models. Econometric Reviews 28(1-3), 170-185.

Zhao, Y. and Joe, H. (2005). Composite likelihood estimation in multivariate data analysis. The Canadian Journal of Statistics 33(2), 335-356. 


\section{LIST OF TABLES}

Table 1: Travel Parties' Participation in Combination of Leisure Activities

Table 2: Composite Maximum Likelihood Estimation Results

Table 3: Correlation Matrix of Activity Participation Combinations 
Table 1: Travel Parties' Participation in Combination of Leisure Activities

\begin{tabular}{|c|c|c|c|c|c|c|c|c|c|}
\hline & \multicolumn{8}{|c|}{ Percentage of Travel Parties Participating In... } \\
\hline & & $\begin{array}{c}\text { Cultural } \\
\text { Activities }\end{array}$ & $\begin{array}{c}\text { Touring } \\
\text { Activities }\end{array}$ & $\begin{array}{l}\text { Shopping } \\
\text { Activities }\end{array}$ & $\begin{array}{c}\text { Sightseeing } \\
\text { Activities }\end{array}$ & $\begin{array}{c}\text { Wildlife } \\
\text { Experience } \\
\text { Activities }\end{array}$ & $\begin{array}{c}\text { Land } \\
\text { Recreation } \\
\text { Activities }\end{array}$ & $\begin{array}{c}\text { Water } \\
\text { Recreation } \\
\text { Activities }\end{array}$ & $\begin{array}{c}\text { Hunting/ } \\
\text { Fishing } \\
\text { Activities }\end{array}$ \\
\hline \multirow{8}{*}{ 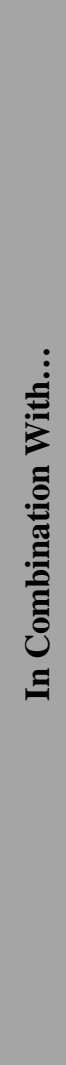 } & $\begin{array}{l}\text { Cultural } \\
\text { Activities }\end{array}$ & $0.00 \%$ & $40.87 \%$ & $39.10 \%$ & $49.59 \%$ & $43.73 \%$ & $42.10 \%$ & $20.57 \%$ & $13.62 \%$ \\
\hline & $\begin{array}{l}\text { Touring } \\
\text { Activities }\end{array}$ & - & $0.41 \%$ & $44.96 \%$ & $58.58 \%$ & $51.77 \%$ & $47.82 \%$ & $24.93 \%$ & $17.57 \%$ \\
\hline & $\begin{array}{l}\text { Shopping } \\
\text { Activities }\end{array}$ & - & - & $0.00 \%$ & $57.63 \%$ & $50.41 \%$ & $46.59 \%$ & $22.75 \%$ & $14.71 \%$ \\
\hline & $\begin{array}{c}\text { Sightseeing } \\
\text { Activities }\end{array}$ & - & - & - & $0.27 \%$ & $67.30 \%$ & $62.67 \%$ & $28.47 \%$ & $22.21 \%$ \\
\hline & $\begin{array}{c}\text { Wildlife } \\
\text { Experience } \\
\text { Activities }\end{array}$ & - & - & - & - & $0.00 \%$ & $58.99 \%$ & $27.93 \%$ & $43.73 \%$ \\
\hline & $\begin{array}{c}\text { Land } \\
\text { Recreation } \\
\text { Activities }\end{array}$ & - & - & - & - & - & $0.27 \%$ & $27.25 \%$ & $20.71 \%$ \\
\hline & $\begin{array}{c}\text { Water } \\
\text { Recreation } \\
\text { Activities }\end{array}$ & - & - & - & - & - & - & $0.27 \%$ & $15.40 \%$ \\
\hline & $\begin{array}{l}\text { Hunting/ } \\
\text { Fishing } \\
\text { Activities }\end{array}$ & - & - & - & - & - & - & - & $1.36 \%$ \\
\hline
\end{tabular}


Table 2: Composite Maximum Likelihood Estimation Results

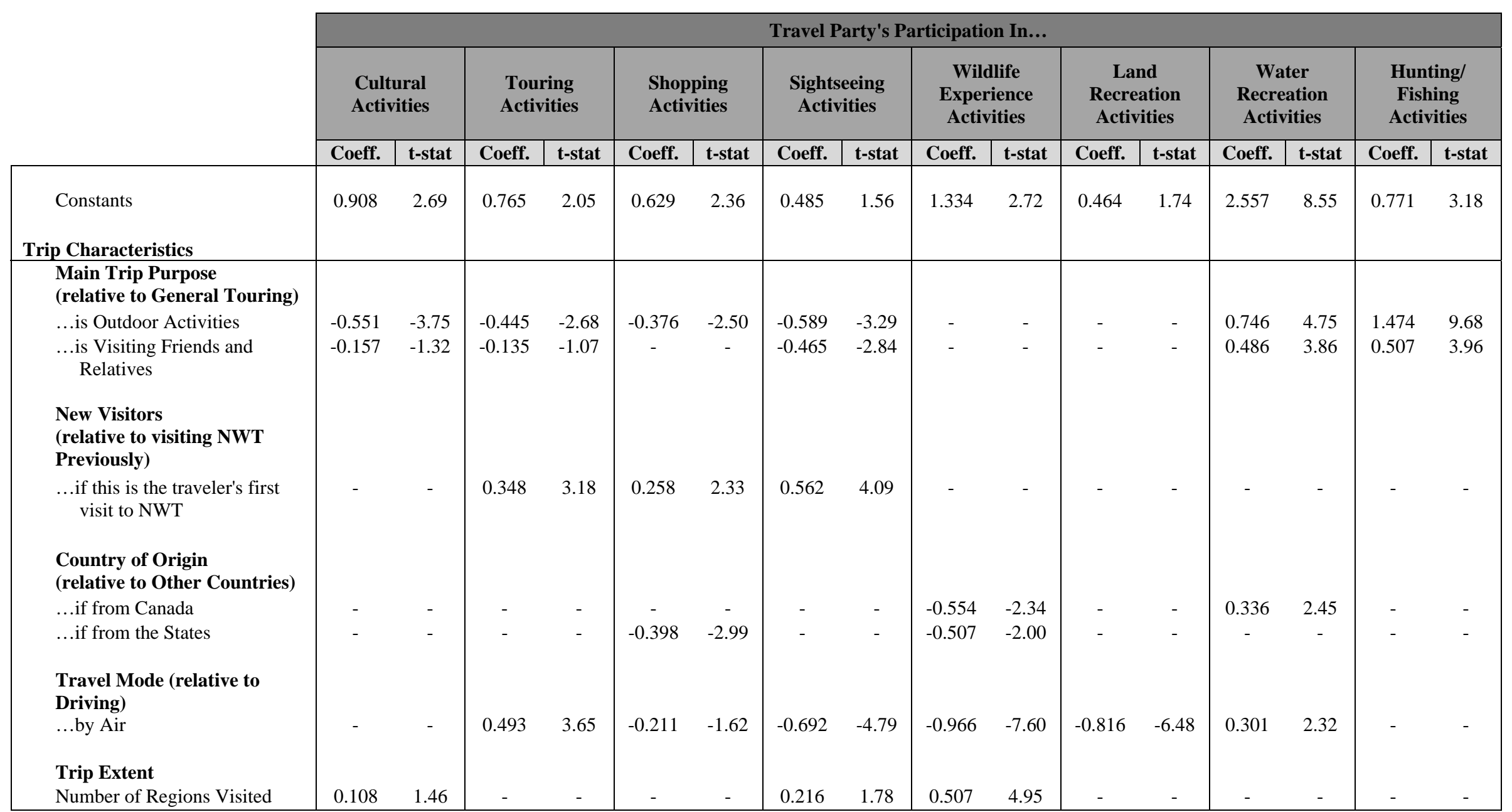


Table 2: Composite Maximum Likelihood Estimation Results (Continued)

\begin{tabular}{|c|c|c|c|c|c|c|c|c|c|c|c|c|c|c|c|c|}
\hline & \multicolumn{16}{|c|}{ Travel Party's Participation In... } \\
\hline & \multicolumn{2}{|c|}{$\begin{array}{l}\text { Cultural } \\
\text { Activities }\end{array}$} & \multicolumn{2}{|c|}{$\begin{array}{c}\text { Touring } \\
\text { Activities }\end{array}$} & \multicolumn{2}{|c|}{$\begin{array}{l}\text { Shopping } \\
\text { Activities }\end{array}$} & \multicolumn{2}{|c|}{$\begin{array}{c}\text { Sightseeing } \\
\text { Activities }\end{array}$} & \multicolumn{2}{|c|}{$\begin{array}{l}\text { Wildlife } \\
\text { Experience } \\
\text { Activities }\end{array}$} & \multicolumn{2}{|c|}{$\begin{array}{c}\text { Land } \\
\text { Recreation } \\
\text { Activities }\end{array}$} & \multicolumn{2}{|c|}{$\begin{array}{l}\text { Water } \\
\text { Recreation } \\
\text { Activities }\end{array}$} & \multicolumn{2}{|c|}{$\begin{array}{l}\text { Hunting/ } \\
\text { Fishing } \\
\text { Activities }\end{array}$} \\
\hline & Coeff. & t-stat & Coeff. & t-stat & Coeff. & t-stat & Coeff. & t-stat & Coeff. & t-stat & Coeff. & t-stat & Coeff. & t-stat & Coeff. & t-stat \\
\hline \multicolumn{17}{|l|}{ Travel Party Composition } \\
\hline $\begin{array}{l}\text { Party Type } \\
\text { (relative to Traveling Alone) }\end{array}$ & & & & & & & & & & & & & & & & \\
\hline ....as a Couple & 0.365 & 2.29 & - & - & 0.176 & 1.40 & - & - & - & - & 0.173 & 1.46 & - & - & - & - \\
\hline ...with Family & 0.315 & 1.83 & - & - & 0.210 & 1.41 & 0.501 & 3.00 & - & - & - & - & - & - & 0.267 & 1.78 \\
\hline ...with Friends & 0.412 & 2.19 & - & - & - & - & - & - & - & - & - & - & - & - & 0.216 & 1.57 \\
\hline ...with Co-Workers & - & - & - & - & - & - & - & - & - & - & - & - & - & - & 1.547 & 1.81 \\
\hline \multicolumn{17}{|l|}{ Number of Children } \\
\hline ....aged 0 to 5 years old & - & - & - & - & - & - & - & - & - & - & - & - & - & - & 0.339 & 1.26 \\
\hline ....aged 6 to 10 years old & - & - & - & - & - & - & - & - & - & - & 0.343 & 1.81 & 0.416 & 2.70 & 0.322 & 2.12 \\
\hline ....aged 11 to 20 years old & - & - & - & - & - & - & - & - & 0.238 & 2.26 & - & - & 0.150 & 1.64 & - & - \\
\hline Number of Adults & & & & & & & & & & & & & & & & \\
\hline ....aged 21 to 30 years old & -0.147 & -1.63 & 0.155 & 1.54 & - & - & -0.239 & -2.41 & 0.342 & 2.94 & 0.208 & 2.01 & 0.249 & 2.50 & - & - \\
\hline ....aged 31 to 50 years old & - & - & 0.103 & 1.49 & - & - & - & - & 0.365 & 4.27 & 0.104 & 1.47 & 0.269 & 3.46 & - & - \\
\hline ....aged 51 or older & 0.115 & 2.39 & - & - & - & - & - & - & 0.336 & 4.20 & - & - & 0.121 & 2.01 & - & - \\
\hline \multicolumn{17}{|l|}{ Traveler Sociodemographics } \\
\hline \multicolumn{17}{|l|}{$\begin{array}{l}\text { Individual Education } \\
\text { (relative to Less Than High } \\
\text { School) }\end{array}$} \\
\hline ...High School or Some College & - & - & - & - & -0.424 & -3.70 & - & - & - & - & - & - & - & - & -0.532 & -2.21 \\
\hline ...College or University & 0.268 & 2.42 & - & - & - & - & 0.336 & 2.27 & - & - & - & - & 0.136 & 1.33 & -0.697 & -2.94 \\
\hline ...Graduate School & 0.301 & 2.11 & - & - & - & - & 0.368 & 1.86 & - & - & - & - & - & - & -0.856 & -3.29 \\
\hline \multicolumn{17}{|l|}{$\begin{array}{l}\text { Annual Individual Income } \\
\text { (relative to Less Than } \$ 30,000 \text { ) }\end{array}$} \\
\hline ...between $\$ 30,000$ and $\$ 49,999$ & -0.639 & -2.84 & -0.472 & -1.98 & - & - & - & - & - & - & - & - & - & - & - & - \\
\hline ...between $\$ 50,000$ and $\$ 69,999$ & -0.342 & -1.54 & -0.399 & -1.68 & -0.219 & -1.53 & - & - & - & - & - & - & - & - & 0.282 & 1.77 \\
\hline ...between $\$ 70,000$ and $\$ 89,999$ & -0.449 & -1.93 & -0.381 & -1.55 & -0.263 & -1.66 & - & - & - & - & - & - & - & - & 0.378 & 2.21 \\
\hline ...greater than $\$ 90,000$ & -0.392 & -1.78 & -0.374 & -1.60 & -0.155 & -1.10 & - & - & - & - & - & - & - & - & 0.195 & 1.29 \\
\hline
\end{tabular}


Table 2: Composite Maximum Likelihood Estimation Results (Continued)

\begin{tabular}{|c|c|c|c|c|c|c|c|c|c|c|c|c|c|c|c|c|}
\hline & \multicolumn{16}{|c|}{ Travel Party's Participation In... } \\
\hline & \multicolumn{2}{|c|}{$\begin{array}{l}\text { Cultural } \\
\text { Activities }\end{array}$} & \multicolumn{2}{|c|}{$\begin{array}{c}\text { Touring } \\
\text { Activities }\end{array}$} & \multicolumn{2}{|c|}{$\begin{array}{l}\text { Shopping } \\
\text { Activities }\end{array}$} & \multicolumn{2}{|c|}{$\begin{array}{l}\text { Sightseeing } \\
\text { Activities }\end{array}$} & \multicolumn{2}{|c|}{$\begin{array}{c}\text { Wildlife } \\
\text { Experience } \\
\text { Activities }\end{array}$} & \multicolumn{2}{|c|}{$\begin{array}{c}\text { Land } \\
\text { Recreation } \\
\text { Activities }\end{array}$} & \multicolumn{2}{|c|}{$\begin{array}{c}\text { Water } \\
\text { Recreation } \\
\text { Activities }\end{array}$} & \multicolumn{2}{|c|}{$\begin{array}{l}\text { Hunting/ } \\
\text { Fishing } \\
\text { Activities }\end{array}$} \\
\hline & Coeff. & t-stat & Coeff. & t-stat & Coeff. & t-stat & Coeff. & t-stat & Coeff. & t-stat & Coeff. & t-stat & Coeff. & t-stat & Coeff. & t-stat \\
\hline \multicolumn{17}{|l|}{ Preferences and Concerns } \\
\hline Importance of Costs & & & & & & & & & & & & & & & & \\
\hline Cost of Accommodations and Meals & 0.130 & 1.03 & - & - & - & - & -0.221 & -1.15 & - & - & 0.181 & 1.26 & - & - & - & - \\
\hline Cost of Travel to Destination & - & - & - & - & - & - & 0.501 & 2.68 & -0.219 & -1.24 & - & - & - & - & - & - \\
\hline \multicolumn{17}{|l|}{ Importance of Personal Experience } \\
\hline Personal Challenges & - & - & -0.399 & -2.85 & -0.232 & -1.87 & - & - & - & - & - & - & -0.254 & -1.84 & - & - \\
\hline Physical Adventure & - & - & 0.257 & 1.82 & - & - & - & - & 0.273 & 2.02 & 0.487 & 3.87 & 0.514 & 3.49 & - & - \\
\hline Meeting New People & 0.359 & 2.17 & 0.324 & 1.82 & - & - & - & - & - & - & - & - & - & - & - & - \\
\hline $\begin{array}{l}\text { Unique or Different Cultural } \\
\text { Experiences }\end{array}$ & - & - & - & - & - & - & 0.188 & 1.06 & - & - & 0.244 & 1.70 & - & - & - & - \\
\hline Learning Opportunities & - & - & 0.324 & 1.64 & 0.260 & 1.29 & - & - & - & - & - & - & 0.651 & 3.14 & - & - \\
\hline Importance of High Quality & & & & & & & & & & & & & & & & \\
\hline Accommodations & & & & & & & & & & & & & & & & \\
\hline Luxury Accommodations & - & - & -0.382 & -2.85 & -0.219 & -1.63 & - & - & -0.432 & -3.13 & -0.396 & -2.94 & -0.255 & -2.12 & - & - \\
\hline High Standards of Cleanliness & - & - & - & - & - & - & - & - & - & - & -0.611 & -3.27 & - & - & - & - \\
\hline Personal Safety & - & - & 0.285 & 1.55 & - & - & - & - & - & - & - & - & 0.322 & 1.70 & - & - \\
\hline \multicolumn{17}{|l|}{ Importance of Entertainment } \\
\hline Relaxing Break From Work & - & - & -0.434 & -3.33 & 0.340 & 2.70 & - & - & - & - & 0.219 & 1.68 & - & - & - & - \\
\hline Having Fun/ Being Entertained & - & - & - & - & -0.265 & -2.24 & - & - & -0.491 & -3.62 & -0.192 & -1.51 & - & - & 0.262 & 2.20 \\
\hline $\begin{array}{l}\text { Exciting Nightlife and } \\
\text { Entertainment }\end{array}$ & - & - & 0.220 & 1.66 & 0.154 & 1.14 & - & - & - & - & - & - & - & - & - & - \\
\hline \multicolumn{17}{|l|}{ Importance of Shopping } \\
\hline Interesting Shopping & - & - & - & - & 0.533 & 4.34 & 0.439 & 2.63 & - & - & -0.182 & -1.49 & - & - & - & - \\
\hline Opportunity to Purchase Crafts/Art & - & - & - & - & 0.325 & 2.70 & 0.187 & 1.21 & 0.241 & 1.89 & - & - & - & - & - & - \\
\hline \multicolumn{17}{|l|}{ Importance of Touring } \\
\hline $\begin{array}{l}\text { Complete Package Tours to } \\
\text { Destination }\end{array}$ & - & - & - & - & -0.178 & -1.44 & -0.532 & -3.30 & - & - & -0.211 & -1.58 & - & - & - & - \\
\hline Organized Tours at Destination & - & - & 0.299 & 2.75 & 0.168 & 1.39 & 0.348 & 2.33 & 0.176 & 1.35 & 0.154 & 1.22 & - & - & -0.254 & -2.27 \\
\hline \multicolumn{17}{|l|}{ Importance of Nature } \\
\hline Experiencing Nature with a Guide & - & - & - & - & 0.117 & 1.07 & - & - & - & - & -0.152 & -1.31 & - & - & - & - \\
\hline Outstanding Scenery & - & - & - & - & - & - & - & - & 0.784 & 1.89 & - & - & - & - & - & - \\
\hline Viewing Wildlife & 0.359 & 1.68 & 0.282 & 1.20 & - & - & - & - & 0.694 & 2.69 & 0.619 & 2.63 & - & - & - & - \\
\hline Parks and Wilderness Areas & - & - & 0.292 & 1.42 & 0.297 & 1.53 & 0.471 & 2.42 & - & - & 0.278 & 1.43 & - & - & - & - \\
\hline \multicolumn{17}{|l|}{ Importance of Climate } \\
\hline Warm Sunny Climate & - & - & - & - & - & - & - & - & - & - & 0.451 & 3.75 & - & - & - & - \\
\hline Reliable Weather & - & - & - & - & 0.173 & 1.54 & - & - & 0.227 & 1.76 & - & - & - & - & - & - \\
\hline
\end{tabular}


Table 3: Correlation Matrix of Activity Participation Combinations

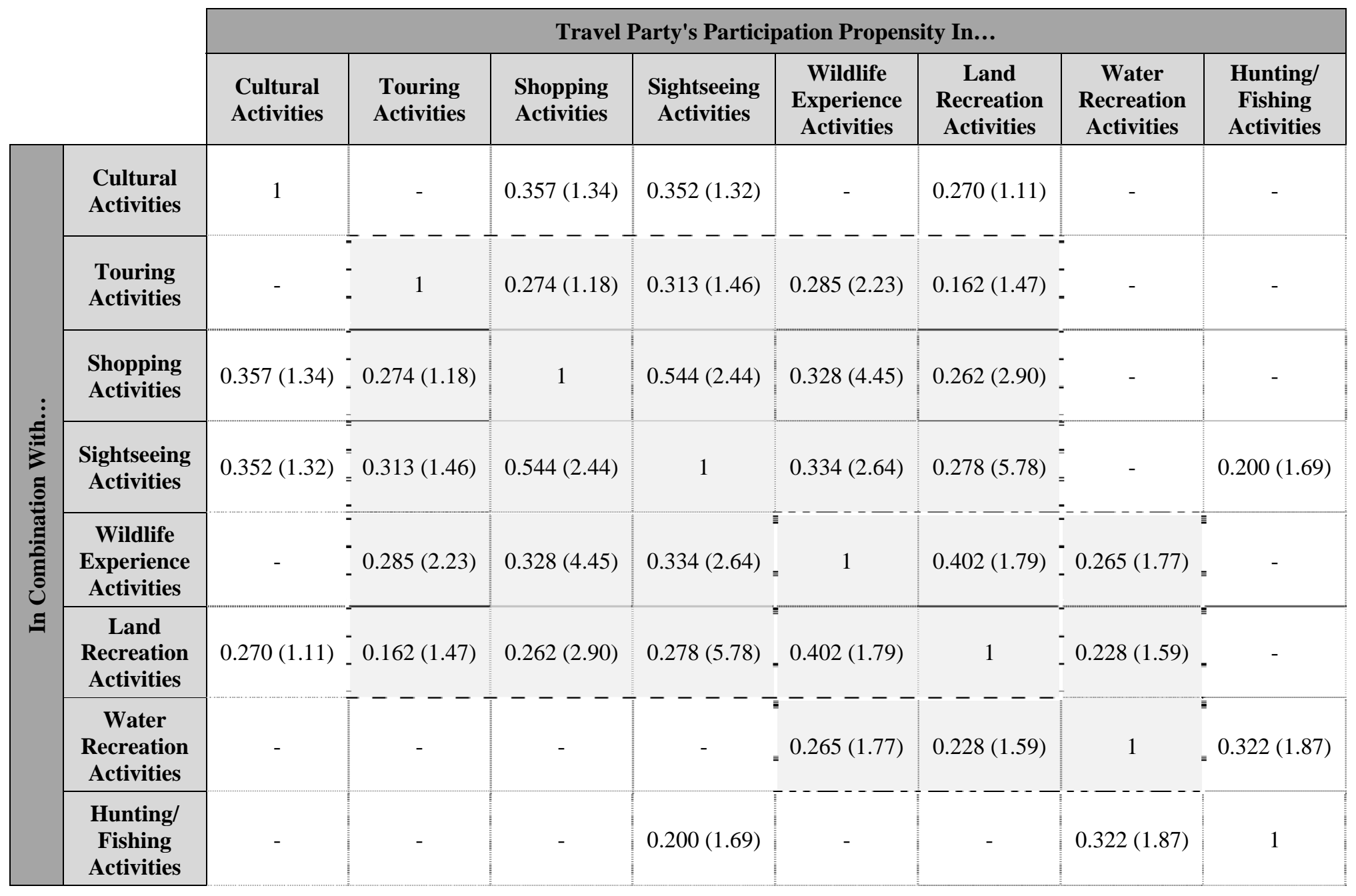

